\title{
Classification of Maize Landraces from Shikoku and Kyushu, Japan, Based on Phenotypic Characteristics
}

\author{
Ko HARADA ${ }^{1 *}$, Nguyen Van HUAN ${ }^{1,2}$ and Hideto UENO ${ }^{1}$ \\ ${ }^{1}$ Faculty of Agriculture, Ehime University (Matsuyama, Ehime 790-8566, Japan)
}

\begin{abstract}
We examined 40 accessions of maize collected from Shikoku (36) and Kyushu (4) for 18 characteristics of growth, yield, and ear morphology. Nested ANOVA revealed significant variations among the accessions in most of the characteristics. Principal component analysis of 11 representative characteristics revealed that the first 4 principal components (Eigenvalues $>1$ ) accounted for $75.2 \%$ of the total variation. These 4 components indicated earliness of growth, ear morphology, yield ability, and seed size in decreasing order of effects. Using cluster analysis based on the 4 components, we identified at least 8 cultivars, which we tentatively assigned to 5 cultivar groups defined in the $1960 \mathrm{~s}$. The accessions from Shikoku are rich in phenotypic variations and include landraces that have not been mentioned before.
\end{abstract}

Discipline: Genetic Resources

Additional key words: cluster analysis, PCA, shifting cultivation, Zea mays L.

\section{Introduction}

In Shikoku, Japan, intensive shifting cultivation was practiced until the $1960 \mathrm{~s}^{11}$. Soma ${ }^{12}$ classified the shifting fields into spring-burning fields (western part of the Shikoku Mountains in Kochi and Ehime prefectures, centering on Niyodo district) and summer-burning fields (mountainous area of Iya district, Tokushima Prefecture). Cultivation of maize as a major crop characterized the former ${ }^{12}$. Only very limited cultivation of maize is known from other shifting fields in Japan, mainly in Kyushu, in Tohoku, and at the foot of Mt. Fuji².

The National Institute of Agricultural Sciences collected local maize landraces in the $1950 \mathrm{~s}$ and $1960 \mathrm{~s}^{2}$, including 254 in Shikoku. From their growth and morphological characteristics in 3 experimental fields they were classified into 24 cultivars in 10 cultivar groups ${ }^{2}$. The variation was greatest among the accessions from Shikoku. This was attributed to the diversity of geography, fields, and cropping systems peculiar to this mountainous area ${ }^{2}$.

It is said that maize was first introduced into Japan at the end of the 16th century (around 1580) in Nagasaki by the Portuguese ${ }^{7}$. Maize was mentioned as one of the commonly grown crops in the lowlands of Shikoku in Shinmin Kangetsushu, one of the oldest known agriculture textbooks, which was written at the beginning of 17th century ${ }^{13}$. One of the oldest records of maize grown on mountainsides (Ikegawa, Kochi) appeared in $1784^{3}$. The maize presently grown in the mountain villages of Shikoku is said to be Caribbean flint (Zea mays L. var. indurata Sturt) ${ }^{2}$, the same as introduced into Japan in the Middle Ages. Modern cultivars were introduced after the Meiji Era. This implies that maize has been grown in Shikoku for approximately 400 years. Our interview research also found that in more than $80 \%$ of cases, maize landraces have been perpetuated from generation to generation $^{6}$. Maize landraces are found in many areas of the Shikoku Mountains, probably having been distributed to different areas with the movement of villagers or by trade. Such traditional landraces are now found only in restricted areas in mountain villages. Because these landraces have been selected by farmers and adapted to various environmental conditions through several hundred years of cultivation, they offer valuable genetic resources.

\footnotetext{
Present address:

${ }^{2}$ Key Laboratory of Plant Cell Technology, Institute of Agricultural Genetics, Ministry of Agriculture and Rural Development, Vietnam (Tu Liem, Hanoi, Vietnam)

*Corresponding author: e-mail kharada@agr.ehime-u.ac.jp

Received 13 September 2006; accepted 25 November 2008.
} 
Mochizuki ${ }^{9}$ first used principal component analysis (PCA) in the 1960s for the classification of Japanese landraces of Caribbean flint corn. Choosing 10 agronomically important characters, he classified 57 accessions collected from Shikoku into 14 cultivars in 4 groups. He showed that classification based on this method contributed significantly to the selection of breeding materials, especially for superior combining ability. Unfortunately, his accessions were no longer available in 2008. Because these landraces are important not only as genetic resources for breeding, but also for population genetics studies to investigate the diversification and fixation process of landraces, we started collecting landraces in 2000.

Here, as the first step in evaluating these materials as genetic resources, we characterized traits associated with growth, yield, and ear morphology of maize accessions collected in Shikoku and the Kyushu Mountains, where shifting cultivation had also been practiced. We also classified the accessions into cultivars by PCA and compared the classification with the previous one ${ }^{2}$ to identify landraces still conserved in the Shikoku Mountains.

\section{Materials and methods}

\section{Maize landraces}

Seeds of maize landraces were collected from 2000 to 2007 from mountain villages in Ehime, Kochi, and Tokushima prefectures in Shikoku (Table 1, Fig. 1). Additional seeds were collected from mountain villages in Kyushu. A total of 105 accessions were identified by the end of 2007. Seeds were stored in a refrigerator at the Faculty of Agriculture, Ehime University. Here we used 40 accessions: 8 from Ehime, 19 from Kochi, 9 from Tokushima, and 4 from Kumamoto and Miyazaki prefectures in Kyushu.

\section{Field experiments}

On 2004 April 14, 20 maize seeds per accession were sown in paper cups (Jiffy pot, $\varnothing 5.5 \mathrm{~cm}$; 1 seed per cup) and germinated in a greenhouse. Twelve healthy seedlings per accession were chosen and transferred to the experimental farm of Ehime University in Hojo, Matsuyama, on April 30. The 12 plants were divided into 3 groups of 4. The planting order was randomized in all groups. Plants were placed $30 \mathrm{~cm}$ apart in rows $90 \mathrm{~cm}$ apart in a field measuring $20 \mathrm{~m} \times 25 \mathrm{~m}$. Fertilizer was applied at $3 \mathrm{~g}$ nitrogen, $10 \mathrm{~g}$ phosphate, and $10 \mathrm{~g}$ potassium per $\mathrm{m}^{2}$.

\section{Measurement of growth characteristics}

Various characteristics of plant growth were mea- sured until the plants produced mature seeds. Cumulative days until tasseling and silking (DTS and DSK, respectively) were recorded for each plant. Plant height (from the ground to the top of plants) was measured on June 1, 7, 14, 21 and 28 and July 5 and 12. Soil and Plant Analyzer Development (SPAD) values were measured with a Minolta SPAD-502 leaf chlorophyll meter (Minolta Co. Ltd., Osaka, Japan) at 15 points per plant on June 1 and 30 (SPD1 and SPD2, respectively).

\section{Measurement of yield characteristics and ear morphology}

Fully matured ears were harvested in July and August. The ears were dried in open air for 1 to 2 months. We measured or counted the diameter of the ear at the base (DBT) and the top (DTP), ear length (ELG), number of rows per ear (NRW), number of grains per row (NGR), number of grains per ear (NGE), total grain weight per ear (WGE), total number of grains per plant (NGP), and total grain weight per plant, or yield (YLD). We calculated the conical index $\mathrm{CON}=(\mathrm{DBT}-\mathrm{DTP}) / \mathrm{ELG}$, and the 100 -grain weight as GRW $=(\mathrm{WGE} \times 100) / \mathrm{NGE}$.

\section{Data analysis}

Analysis of variance (ANOVA) and multivariate PCA and cluster analysis were conducted with JMP v. 5 software (SAS International, USA). Nested ANOVA was used for analyzing growth characteristics according to the following model:

$$
x_{i j k}=\mu+\alpha_{i}+\beta_{i j}+\varepsilon_{i j k}
$$

where $x_{i j k}$ is the observed value of the $k$-th plant of the $j$-th replication in the $i$-th accession; $\mu$ is the accession mean; $\alpha_{i}$ and $\beta_{i j}$ are the effects of accession $i$ and replication $j$ within accession $i$; and $\varepsilon_{i j k}$ is the error associated with the $x_{i j k}$-th observation. Nested ANOVA was extended for analysis of the yield and ear morphological characteristics to enable addition of the plant effect within a replication. The following model was used for the analysis:

$$
x_{i j k l}=\mu+\alpha_{i}+\beta_{i j}+\varepsilon_{i j k}+\gamma_{i j k l}
$$

where $x_{i j k l}$ is the observation of the $l$-th ear of the $k$-th plant in the $j$-th replication in the $i$-th accession; $\mu$ is the accession mean; $\alpha_{i}, \beta_{i j}$, and $\varepsilon_{i j k}$ are the effects of accession $i$, replication $j$ within accession $i$, and plant $k$ within replication $j$, respectively; and $\gamma_{i j k l}$ is the error associated with the $x_{i j k l}$-th observation.

Parameters A1 (estimated plant height at maturity), A2 (growth rate), and A3 (days to onset of plant growth) were determined by fitting the periodic plant height mea- 
surements to:

$$
y=\frac{A 1}{1+\exp (-A 2 \cdot x+A 3)}
$$

where $x$ is the cumulative days and $y$ is the height in centimeters. Fitting was performed using Kyplot software (KyensLab, Tokyo, Japan).

Table 1. Sampling sites of local maize accessions

\begin{tabular}{|c|c|c|c|c|c|c|}
\hline Prefecture & Accession & Town/village & Location & Longitude & Latitude & Alt. (m) \\
\hline \multirow[t]{8}{*}{ Ehime } & E01 & Mikawa & Nanatori & $33^{\circ} 38^{\prime} 25.7^{\prime \prime}$ & $132^{\circ} 59^{\prime} 25.3^{\prime \prime}$ & 438 \\
\hline & E07 & Hirota & Nakanokawa & $33^{\circ} 38^{\prime} 26.3^{\prime \prime}$ & $132^{\circ} 47^{\prime} 30.1^{\prime \prime}$ & 319 \\
\hline & E08 & Hirota & Takaichi & $33^{\circ} 37^{\prime} 28.9^{\prime \prime}$ & $132^{\circ} 46^{\prime} 14.7^{\prime \prime}$ & 515 \\
\hline & E09 & Oda & Tateishi & $33^{\circ} 33^{\prime} 33.5^{\prime \prime}$ & $132^{\circ} 45^{\prime} 50.1^{\prime \prime}$ & 231 \\
\hline & E10 & Oda & Kametani & $33^{\circ} 34^{\prime} 26.3^{\prime \prime}$ & $132^{\circ} 50^{\prime} 54.9^{\prime \prime}$ & 277 \\
\hline & E13 & Hijikawa & Kamisagaya & $33^{\circ} 28^{\prime} 33.4^{\prime \prime}$ & $132^{\circ} 44^{\prime} 01.3^{\prime \prime}$ & 478 \\
\hline & E14 & Nomura & Sougawa & $33^{\circ} 28^{\prime} 11.4^{\prime \prime}$ & $132^{\circ} 47^{\prime} 41.5^{\prime \prime}$ & 696 \\
\hline & E15 & Nomura & Komatsu & $33^{\circ} 29^{\prime} 10.7^{\prime \prime}$ & $132^{\circ} 49^{\prime} 22.4^{\prime \prime}$ & 624 \\
\hline \multirow[t]{19}{*}{ Kochi } & K01 & Agawa & Kitagawa & $33^{\circ} 34^{\prime} 49.4^{\prime \prime}$ & $133^{\circ} 07^{\prime} 07.8^{\prime \prime}$ & 470 \\
\hline & K08 & Higashituno & Kuchimegaichi & $33^{\circ} 27^{\prime} 06.6^{\prime \prime}$ & $133^{\circ} 01^{\prime} 51.2^{\prime \prime}$ & 704 \\
\hline & K15 & Agawa & Tooda & $33^{\circ} 36^{\prime} 41.5^{\prime \prime}$ & $133^{\circ} 16^{\prime} 46.7^{\prime \prime}$ & 311 \\
\hline & K20 & Hayama & Oono & $33^{\circ} 26^{\prime} 21.0^{\prime \prime}$ & $133^{\circ} 10^{\prime} 17.8^{\prime \prime}$ & 204 \\
\hline & K22 & Ikegawa & Tubayama & $33^{\circ} 40^{\prime} 18.6^{\prime \prime}$ & $133^{\circ} 08^{\prime} 48.8^{\prime \prime}$ & 428 \\
\hline & K27 & Ino & Nakoi & $33^{\circ} 36^{\prime} 34.7^{\prime \prime}$ & $133^{\circ} 23^{\prime} 13.6^{\prime \prime}$ & 376 \\
\hline & K28 & Taisyo & Shimotsui & $33^{\circ} 17^{\prime} 22.1^{\prime \prime}$ & $132^{\circ} 56^{\prime} 00.6^{\prime \prime}$ & 326 \\
\hline & K31 & Yusuhara & Nagano & $33^{\circ} 27^{\prime} 11.6^{\prime \prime}$ & $132^{\circ} 56^{\prime} 28.8^{\prime \prime}$ & 709 \\
\hline & K32 & Taisho & Kamioka & $33^{\circ} 10^{\prime} 42.0^{\prime \prime}$ & $133^{\circ} 00^{\prime} 49.6^{\prime \prime}$ & 148 \\
\hline & K33 & Yusuhara & Higashigawa & $33^{\circ} 26^{\prime} 18.6^{\prime \prime}$ & $132^{\circ} 53^{\prime} 33.2^{\prime \prime}$ & 625 \\
\hline & K35 & Ootoyo & Shimomyo & $33^{\circ} 49^{\prime} 23.3^{\prime \prime}$ & $133^{\circ} 40^{\prime} 09.7^{\prime \prime}$ & 442 \\
\hline & K36 & Yusuhara & Tanono & $33^{\circ} 25^{\prime} 46.8^{\prime \prime}$ & $132^{\circ} 56^{\prime} 44.7^{\prime \prime}$ & 595 \\
\hline & K37 & Yusuhara & Kochimuki & $33^{\circ} 25^{\prime} 28.8^{\prime \prime}$ & $132^{\circ} 53^{\prime} 20.7^{\prime \prime}$ & 684 \\
\hline & K41 & Kubokawa & Oreai & $33^{\circ} 15^{\prime} 32.2^{\prime \prime}$ & $133^{\circ} 03^{\prime} 02.2^{\prime \prime}$ & 423 \\
\hline & K42 & Higashituno & Chikaraishi & $33^{\circ} 24^{\prime} 09.1^{\prime \prime}$ & $133^{\circ} 02^{\prime} 56.9^{\prime \prime}$ & 247 \\
\hline & K46 & Motoyama & Huruta & $33^{\circ} 44^{\prime} 30.2^{\prime \prime}$ & $133^{\circ} 37^{\prime} 24.4^{\prime \prime}$ & 541 \\
\hline & K47 & Tosa & Wada & $33^{\circ} 44^{\prime} 05.3^{\prime \prime}$ & $133^{\circ} 30^{\prime} 42.4^{\prime \prime}$ & 581 \\
\hline & K49 & Tosa & Nishi-ishiwara & $33^{\circ} 41^{\prime} 38.4^{\prime \prime}$ & $133^{\circ} 27^{\prime} 43.2^{\prime \prime}$ & 349 \\
\hline & K51 & Tosa & Yanagino & $33^{\circ} 37^{\prime} 26.0^{\prime \prime}$ & $133^{\circ} 14^{\prime} 35.8^{\prime \prime}$ & 475 \\
\hline \multirow[t]{9}{*}{ Tokushima } & T02 & Ichiu & Kuwadaira & $33^{\circ} 53^{\prime} 24.1^{\prime \prime}$ & $134^{\circ} 04^{\prime} 12.8^{\prime \prime}$ & 829 \\
\hline & $\mathrm{T} 12$ & Nishi-iya & Tonotani & $33^{\circ} 53^{\prime} 11.3^{\prime \prime}$ & $133^{\circ} 48^{\prime} 28.5^{\prime \prime}$ & 496 \\
\hline & $\mathrm{T} 14$ & Yamashiro & Awayama & $33^{\circ} 54^{\prime} 00.8^{\prime \prime}$ & $133^{\circ} 42^{\prime} 58.6^{\prime \prime}$ & 526 \\
\hline & $\mathrm{T} 15$ & Higashi-iya & Sugeoi & $33^{\circ} 52^{\prime} 13.6^{\prime \prime}$ & $133^{\circ} 59^{\prime} 38.9^{\prime \prime}$ & 843 \\
\hline & $\mathrm{T} 16$ & Higashi-iya & Ooeda & $33^{\circ} 51^{\prime} 49.8^{\prime \prime}$ & $133^{\circ} 53^{\prime} 55.1^{\prime \prime}$ & 635 \\
\hline & T19 & Kisawa & Touyama & $33^{\circ} 49^{\prime} 55.9^{\prime \prime}$ & $134^{\circ} 18^{\prime} 38.5^{\prime \prime}$ & 648 \\
\hline & $\mathrm{T} 20$ & Kitou & Kitagawa & $33^{\circ} 46^{\prime} 14.1^{\prime \prime}$ & $134^{\circ} 06^{\prime} 09.3^{\prime \prime}$ & 485 \\
\hline & $\mathrm{T} 22$ & Kitou & Izuhara & $33^{\circ} 46^{\prime} 21.5^{\prime \prime}$ & $134^{\circ} 12^{\prime} 25.3^{\prime \prime}$ & 352 \\
\hline & $\mathrm{T} 25$ & Kaminaka & Kagehira & $33^{\circ} 48^{\prime} 34.0^{\prime \prime}$ & $134^{\circ} 16^{\prime} 41.0^{\prime \prime}$ & 336 \\
\hline \multirow[t]{2}{*}{ Kumamoto } & Kt01 & Ichinomiya & Sanno & $32^{\circ} 57^{\prime} 46.2^{\prime \prime}$ & $131^{\circ} 08^{\prime} 42.6^{\prime \prime}$ & 505 \\
\hline & $\mathrm{Kt02}$ & Namino & Syouchino & $32^{\circ} 57^{\prime} 02.9^{\prime \prime}$ & $131^{\circ} 11^{\prime} 35.6^{\prime \prime}$ & 779 \\
\hline \multirow[t]{2}{*}{ Miyazaki } & Mz01 & Hinata & Tomitaka & $32^{\circ} 25^{\prime} 46.9^{\prime \prime}$ & $131^{\circ} 36^{\prime} 59.5^{\prime \prime}$ & 7 \\
\hline & Mz02 & Gokase & Sankasho & $32^{\circ} 37^{\prime} 52.8^{\prime \prime}$ & $131^{\circ} 13^{\prime} 45.2^{\prime \prime}$ & 717 \\
\hline
\end{tabular}




\section{Results}

Means and standard deviations (SDs) of the growth characteristics were calculated from means of the accessions (Table 2). Coefficients of variation (CVs) were calculated from the means and SDs to compare variations in these characteristics. There were large variations among the accessions, notably in A1. DTS, DSK and A2 also showed relatively large variations. $F$-values of these characteristics were calculated from the results of ANOVA (Table 3). All of the characteristics except SPD1 showed significant differences among accessions. All of the characteristics except A2 showed a significant replication effect.

Means and SDs of the characteristics related to yield and ear morphology were also calculated from means of the accessions (Table 4). CVs were calculated from these values to compare variations in these characteristics. There were large variations among the accessions, especially in NGP and YLD. $F$-values of these characteristics were calculated from the results of ANOVA (Table 5). All characteristics except NGP and YLD $(0.01<P<0.05)$ showed highly significant differences $(P<0.01)$ among accessions. The replication effect was highly significant in DTP, NGP, and YLD, but was marginal $(0.01<P<$ 0.05 ) in CON, NGE, and GRW. None of the characteristics associated with ear morphology showed a significant difference among plants within replications.

Coefficients of correlation between these characteristics, including altitude of sampling sites (ALT), were calculated (data not shown). ALT showed no correlation with any of the plant characteristics. Some pairs of characteristics showed very strong positive correlations, notably DTS-DSK, DBT-DTP, NGR-ELG, WGE-NGE, and

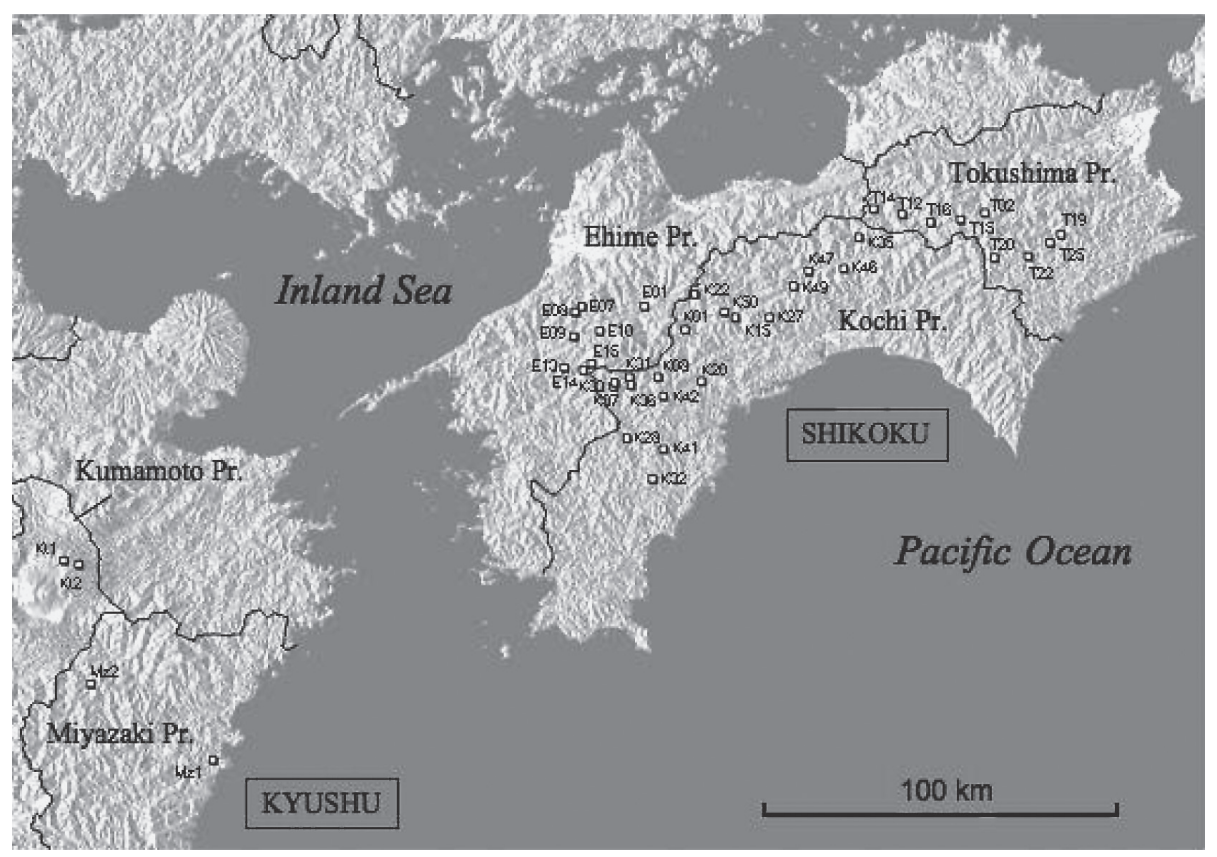

Fig. 1. Sites where maize landrace accessions were collected in Shikoku and Kyushu Numbers correspond to accession numbers.

Table 2. Means and standard deviations of growth characteristics of local maize accessions

\begin{tabular}{ccccccc}
\hline \hline $\begin{array}{c}\text { DTS } \\
\text { (day) }\end{array}$ & $\begin{array}{c}\text { DSK } \\
(\text { day })\end{array}$ & $\begin{array}{c}\text { A1 } \\
(\mathrm{cm})\end{array}$ & A2 & $\begin{array}{c}\text { A3 } \\
(\text { day })\end{array}$ & SPD1 & SPD2 \\
\hline $\begin{array}{c}74.2 \pm 5.31 \\
(7.16)\end{array}$ & $\begin{array}{c}81.0 \pm 6.82 \\
(8.42)\end{array}$ & $\begin{array}{c}220.5 \pm 25.6 \\
(11.6)\end{array}$ & $\begin{array}{c}0.104 \pm 0.008 \\
(7.69)\end{array}$ & $\begin{array}{c}5.84 \pm 0.31 \\
(5.31)\end{array}$ & $\begin{array}{c}44.7 \pm 2.77 \\
(6.20)\end{array}$ & $\begin{array}{c}50.2 \pm 2.97 \\
(5.92)\end{array}$ \\
\hline
\end{tabular}

DTS: cumulative days until tasseling, DSK: cumulative days until silking, A1: estimated plant height at maturity, A2: growth rate, A3: onset of plant growth, SPD1: SPAD value on June 1, SPD2: SPAD value on June 30. Means \pm standard deviations were calculated from means of accessions. Coefficients of variation (\%) are shown in parentheses. 
Table 3. F-values of growth characteristics of local maize accessions obtained from results of nested ANOVA

\begin{tabular}{lcc}
\hline \hline \multirow{2}{*}{ Characteristic } & \multicolumn{2}{c}{ Source of variation } \\
\cline { 2 - 3 } & Accession & Replication \\
\hline DTS & $12.58^{* * *}$ & $3.71^{* * *}$ \\
DSK & $26.28^{* * *}$ & $1.51^{* *}$ \\
A1 & $8.00^{* * *}$ & $2.13^{* * *}$ \\
A2 & $7.46^{* * *}$ & 0.98 \\
A3 & $2.31^{* *}$ & $2.07^{* * *}$ \\
SPD1 & 0.85 & $8.69^{* * *}$ \\
SPD2 & $2.29^{* * *}$ & $3.37^{* * *}$ \\
\hline
\end{tabular}

Abbreviations of characteristics are the same as those in Table 2 .

$*, * *$ and $* * *$ indicate significant $F$-values at $P<0.05$, $P<0.01$ and $P<0.001$, respectively.
NGP-YLD $(P<0.0001)$. DTS and DSK also showed a strong positive correlation with $\mathrm{A} 1(P<0.0001)$ and a strong negative correlation with A2 $(P<0.001)$, but were not significantly correlated with A3. DTS and DSK also showed significant correlations with NGE and WGE $(P<$ 0.01). A2 showed a strong negative correlation with A1 $(P<0.0001)$, but a strong positive correlation with A3 $(P<0.0001)$. SPD1 and SPD2 showed a weak positive correlation with each other and with DTS, but no correlations with any of the other characteristics. ELG showed a strong positive correlation with WGE $(P<0.001)$. NGE showed strong positive correlations with NGR, NGP, and YLD $(P<0.001)$. YLD showed strong positive correlations with NGE and WGE $(P<0.001)$.

We used PCA to classify the accessions by their growth, yield, and ear morphological traits (Table 6). Among the characteristics showing a highly significant

Table 4. Means and standard deviations of yield-related characteristics and ear morphology of local maize accessions

\begin{tabular}{ccccccccccc}
\hline \hline $\begin{array}{c}\text { DBT } \\
(\mathrm{mm})\end{array}$ & $\begin{array}{c}\text { DTP } \\
(\mathrm{mm})\end{array}$ & $\begin{array}{c}\text { ELG } \\
(\mathrm{mm})\end{array}$ & CON & NRW & NGR & NGE & $\begin{array}{c}\text { WGE } \\
(\mathrm{g})\end{array}$ & $\begin{array}{c}\text { GRW } \\
(\mathrm{g})\end{array}$ & $\begin{array}{c}\text { NGP } \\
\text { YLD } \\
(\mathrm{g})\end{array}$ \\
\hline $\begin{array}{c}42.8 \pm 3.6 \\
(8.4)\end{array}$ & $\begin{array}{c}31.5 \pm 2.1 \\
(6.7)\end{array}$ & $\begin{array}{c}144.8 \pm 17.7 \\
(12.2)\end{array}$ & $\begin{array}{ccccccc}0.080 \pm 0.019 \\
(23.8)\end{array}$ & $\begin{array}{c}13.4 \pm 1.38 \\
(10.3)\end{array}$ & $\begin{array}{c}27.6 \pm 3.42 \\
(12.4)\end{array}$ & $\begin{array}{c}288.8 \pm 57.0 \\
(19.7)\end{array}$ & $\begin{array}{c}66.8 \pm 14.7 \\
(22.0)\end{array}$ & $\begin{array}{c}23.0 \pm 2.30 \\
(10.0)\end{array}$ & $\begin{array}{c}413.0 \pm 122.2 \\
(29.6)\end{array}$ & $\begin{array}{c}95.3 \pm 28.3 \\
(29.7)\end{array}$ \\
\hline
\end{tabular}

DBT: diameter of ear at base, DTP: diameter of ear at top, ELG: ear length, CON: conical index ((DTP - DBT) / ELG), NRW: number of rows, NGR: number of grains per row, NGE: number of grains per ear, WGE: total weight of grains per ear, GRW: 100-grain weight, NGP: total number of grains, YLD: total grain weight per plant. Means \pm standard were calculated from means of accessions. Coefficients of variation (\%) are shown in parentheses.

Table 5. $F$-values of yield-related characteristics and ear morphology of local maize accessions obtained from results of nested ANOVA

\begin{tabular}{llll}
\hline \hline \multirow{2}{*}{ Characteristic } & \multicolumn{3}{c}{ Source of variation } \\
\cline { 2 - 4 } & Accession & Replication & Plant \\
\hline DBT & $4.79^{* * *}$ & 1.09 & 0.74 \\
DTP & $5.11^{* * *}$ & $1.75^{* *}$ & 0.83 \\
ELG & $5.40^{* * *}$ & 0.91 & 1.47 \\
CON & $3.88^{* * *}$ & $1.40^{*}$ & 0.63 \\
NRW & $6.06^{* * *}$ & 1.24 & 0.81 \\
NGR & $4.16^{* * *}$ & 1.25 & 1.02 \\
NGE & $2.97^{* * *}$ & $1.40^{*}$ & 1.60 \\
WGE & $3.02^{* * *}$ & 1.12 & 0.94 \\
GRW & $2.15^{* *}$ & $1.47^{*}$ & 0.74 \\
NGP & $1.59^{*}$ & $2.74^{* * *}$ & na \\
YLD & $1.77^{*}$ & $1.85^{* * *}$ & na
\end{tabular}

Abbreviations of characteristics are the same as those in Table 4 .

$*$, ** and *** indicate significant $F$-values at $P<0.05$,

$P<0.01$, and $P<0.001$, respectively. na: not available.
Table 6. Summary of results of principal component analysis

\begin{tabular}{lcccc}
\hline & \multicolumn{4}{c}{ Eigenvector } \\
\cline { 2 - 5 } & PC1 & PC2 & PC3 & PC4 \\
\hline DSK & -0.482 & 0.012 & 0.199 & 0.134 \\
A1 & -0.371 & 0.169 & 0.351 & 0.215 \\
A2 & 0.420 & 0.038 & -0.343 & -0.145 \\
SPD2 & 0.187 & 0.062 & -0.346 & 0.428 \\
DBT & 0.035 & 0.536 & 0.109 & -0.348 \\
ELG & 0.377 & 0.010 & 0.430 & 0.242 \\
CON & -0.161 & 0.459 & -0.247 & -0.411 \\
NRW & -0.145 & 0.470 & -0.085 & 0.280 \\
NGE & 0.287 & 0.425 & 0.061 & 0.177 \\
GRW & 0.230 & -0.088 & 0.500 & -0.459 \\
YLD & 0.301 & 0.245 & 0.284 & 0.251 \\
\hline Eigenvalue & 3.198 & 2.470 & 1.424 & 1.175 \\
Percentage & 29.1 & 22.5 & 12.9 & 10.7 \\
\hline Cumulative percentage & 29.1 & 51.5 & 64.5 & 75.2 \\
\hline
\end{tabular}

Abbreviations of growth and morphological characteristics are the same as those in Tables 2 and 4. 
accession effect, we selected 11 for analysis (DSK, A1, A2, SPD2, DBT, ELG, CON, NRW, NGE, GRW, and YLD). We did not use DTS, A3, DTP, NGR, WGE, or NGP because they showed very strong correlations with DSK, A2, DBT, ELG, NGE, and YLD, respectively. We used DSK instead of DTS because it had a smaller replication effect (Table 3). PCA was based on the correlation matrix. The Eigenvalues for the first 4 principal components (PCs) were $>1$ and accounted for $75.2 \%$ of the total variance. The 3 largest Eigenvectors (absolute values, also the followings) for $\mathrm{PC} 1$ belonged to DSK, A1, and A2; thus, PC1 corresponds to plant size in relation to growing period duration or earliness of growth. The 3 largest Eigenvectors for PC2 belonged to DBT, CON, and NRW; thus, PC2 corresponds to ear shape. Positive values in PC2 were associated with thick conical ears, and negative values with thin cylindrical ears. Because the 3 largest Eigenvectors in PC3 (A1, ELG, and GRW) and PC4 (SPD2, CON, and GRW) overlapped with those of other components, we performed varimax rotation of axes to extract other factors for characterizing the landraces. Factors 1 and 2 again indicated earliness of growth and ear shape, respectively. The 3 largest scores for factor 3 belonged to ELG (-0.799), NGE (-0.699), and YLD (-0.778), indicating yield or reproductive growth ability. The three largest scores for factor 4 belonged to GRW (-0.839), NRW (0.493), and SPD2 (0.554), indicating that seed size also can be used to classify the landraces. Thus, the maize accessions can be characterized by earliness of growth, ear shape, yield ability, and seed size.

Using the 4 PCs, we performed cluster analysis based on Ward's distance method (Fig. 2). Four major clusters (I, II, III, and IV) were identified. Each cluster was further divided into 2 subclusters, a and $\mathrm{b}$. In the case of clusters I, II, and III, the subclusters were split by branching order. Cluster IV was split into 1 branching group (E07, E13, E14, T12, T15, T16, and Mz1) and the balance (E01, E09, E15, K28, and T02). The dendrogram indicates 2 cluster groups: group I-II-III and group IV. The subclusters were projected on a scatter plot constructed of $\mathrm{PC} 1$ as the $x$-axis and $\mathrm{PC} 2$ as the $y$-axis (Fig. 3). From this and other scatter plots combining 2 of the 4 PCs or rotated factors, we characterized these clusters on the basis of the 4 criteria (Table 7). Subclusters Ia, Ib, IIa, $\mathrm{IIb}$, and IIIa were composed of late-growing or intermediate- to late-growing landraces, containing 14 of the 19 accessions from Kochi. Subclusters IIIb, IVa, and IVb were composed of early- or intermediate- to early-growing landraces, containing 6 of the 9 accessions from Ehime.

\section{Discussion}

Characteristics related to growth, seed productivity, and ear morphology showed large variations among the maize accessions (Tables 2,4). Most of the characteristics showed significant differences among accessions (Tables 3, 5). Flowering times (DTS and DSK) were correlated positively with plant height (A1) but negatively with growth rate (A2). This indicates that rapidly growing plants tend to flower and cease growth earlier and to be shorter than slower-growing plants. Days to onset of plant growth (A3) showed a strong positive correlation with A2 but not with A1 or other characteristics. This indicates that rapidly growing plants tend to delay in onset of growth compared with slower-growing plants, but the difference is, in most of the cases, less than one day (Table 2).

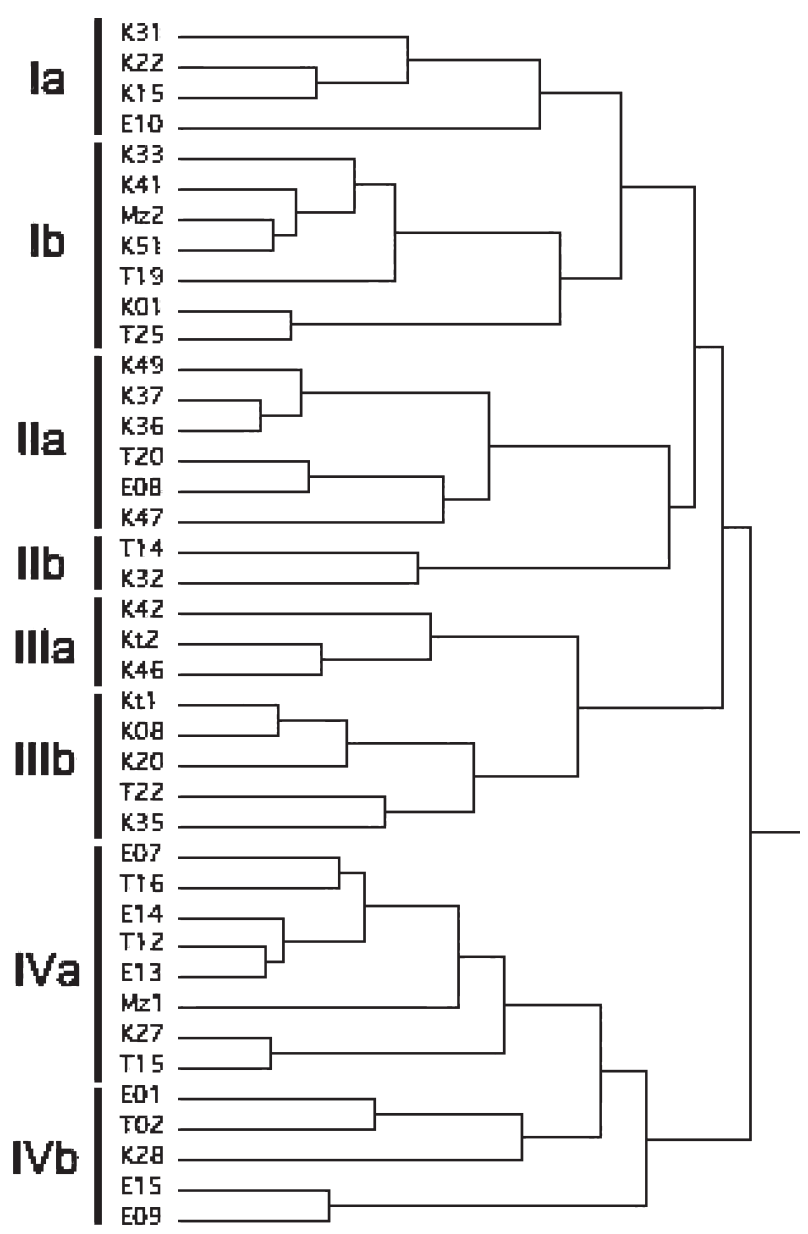

Fig. 2. Dendrogram constructed by using cluster analysis based on the scores of the 4 largest principal components using Ward's distance method Clusters are ordered by the first principal component (PC1), which indicates earliness of growth. 
The number of rows per ear is the primary factor determining ear diameter. The number of rows ranged from 8 to 20 . Ninety-five percent of the numbers of rows ranged from 10 to 18 , and the most frequent numbers were 12 and 14 . These numbers accord with those reported for flint corn landraces in Japan, i.e., 12, 14, and $16^{7}$. Nested ANOVA showed that NRW was significantly different among accessions but not among replications or

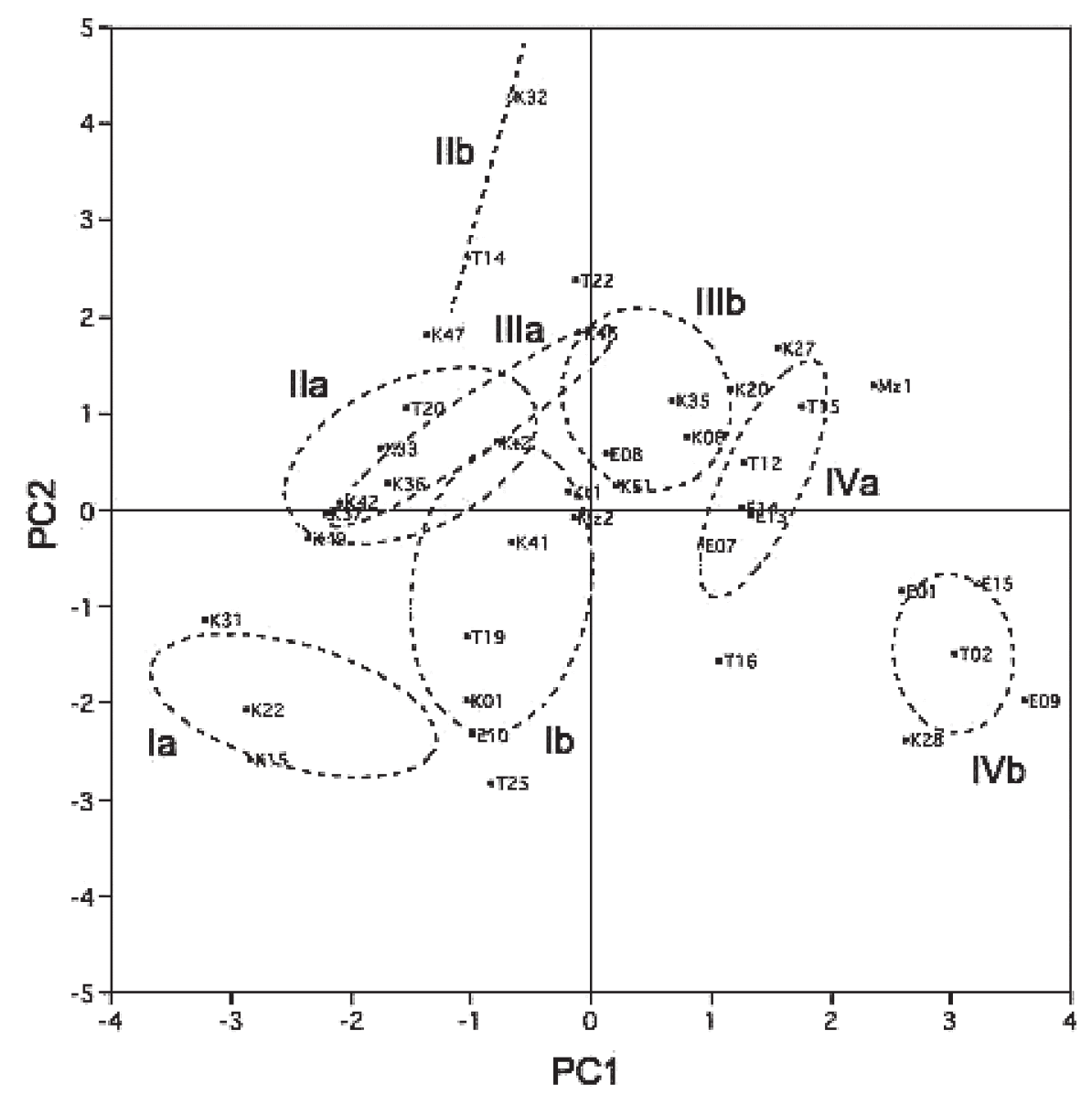

Fig. 3. PCA scatter plot

PC1: principal component 1, PC2: principal component 2. Dotted ellipses indicate clusters (identified by Roman numerals).

Table 7. Classification and characterization of subclusters of maize accessions from Shikoku and Kyushu mountains

\begin{tabular}{|c|c|c|c|c|c|}
\hline \multirow[t]{2}{*}{ Subcluster } & \multirow[t]{2}{*}{ Accession } & \multicolumn{4}{|c|}{ Characteristic } \\
\hline & & Earliness & Ear shape & Yield & Seed size \\
\hline Ia & E10, K15, K22, K31 & Late & Cylindrical & Low & Large \\
\hline $\mathrm{Ib}$ & K01, K33, K41, K51, T19, T25, Mz02 & Int. ${ }^{1)}-$ Late & Int.-Cylindrical & Int.-Low & Large \\
\hline IIa & E08, K36, K37, K47, K49, T20 & Int.-Late & Int.-Conical & Int.-Low & Int.-Small \\
\hline $\mathrm{IIb}$ & K32, T14 & Int.-Late & Conical & Int.-Low & Small \\
\hline IIIa & K42, K46, Kt02 & Int.-Late & Int.-Conical & Int.-High & Int.-Small \\
\hline IIIb & K08, K20, K35,T22, Kt01 & Int.-Early & Int.-Conical & Int.-High & Int.-Small \\
\hline IVa & E07, E13, E14, K27, T12, T15, T16, Mz01 & Early & Cylindrical & Int.-High & Int.-Small \\
\hline $\mathrm{IVb}$ & E01, E09, E15, K28, T02 & Early & Cylindrical & Int.-High & Large \\
\hline
\end{tabular}

1): Intermediate in duration, shape, yield, or size. 
among plants within a replication, although there was some variation among or even within plants. Therefore, this may be considered as a fixed trait. The total yield of plants showed strong positive correlations with the number of grains per ear and the number of grains per plant, but not with 100-grain weight. Highly significant differences in NGP, YLD, and DTP among replications (Table 5) showed that these characteristics are susceptible to environmental influences. None of the characteristics associated with ear morphology showed a significant difference among plants within replications. This may indicate small genetic variation among individual plants within accessions. The SPAD values showed no correlation with any of the growth or reproductive characteristics except for a weak positive correlation with DTS. This suggests that there is a small or no difference in chlorophyll density in the chloroplasts or in plant nitrogen status among the accessions. The large variation in the characteristics associated with vegetative and reproductive growth is probably due to differences in the total leaf area or the efficiency of translocation of assimilation products among the accessions.

We used PCA to classify the landraces. Earliness of growth, which determines plant size, was the most prominent characteristic followed by ear shape, yield ability, and seed size. Using these criteria, we classified the maize accessions into 4 clusters, each with 2 subclusters. In the northern part of the Shikoku Mountains (Ehime Prefecture) maize is planted mostly in mid-May, whereas in the southern part (Kochi Prefecture) most planting has finished by early $\mathrm{May}^{6}$. These practices correspond to our observation that many of the accessions in Ehime are early growing, whereas many in Kochi are late growing.

Among the accessions collected from Shikoku in the 1950s and 1960s, conventional classification identified 24 cultivars in 10 cultivar groups $^{2}$. Mochizuki investigated 10 agronomically important traits of 57 accessions and identified 10 cultivars in 4 major cultivar groups by PCA. His grouping corresponded largely to the traditional classification ${ }^{2}$. This result may provide the basis for categorizing our subclusters as cultivars. Our subclusters IIa, IIb, IIIb, IVa, and IVb (Table 7) showed similar characteristics to those described for 'Kowase', 'Wada', 'Yamakibi', 'Okuuchi', and 'Irerako', respectively'. The other subclusters could not be assigned to any of the formerly identified cultivar groups. Although this grouping is tentative and should be treated with caution because of the wide range of phenotypic variation, our results imply that our accessions include landraces that have not been mentioned before.

The worldwide collection and evaluation of landraces of maize and other important crops has been promoted to conserve and utilize the genetic resources ${ }^{1,4,5,8,10}$. Today, large amounts of genomic information have been accumulated and are accessible on the Internet for most important crops. Our accessions may provide materials with which to study the processes of diversification and fixation of maize landraces by molecular and genomic techniques.

\section{Acknowledgments}

This work was supported in part by a Grant-in-Aid for Scientific Research from the Ministry of Education, Culture, Sports, Science and Technology, Japan (no. 16651115), and a research grant from Ehime University.

\section{References}

1. Costa-Rodrigues, L. (1971) Races of maize in Portugal. Agron. Lusit., 31, 239-284.

2. Department of Physiology and Genetics, NIAS (1979) Collection and characteristics of races of maize in Japan. Misc. Publ. Nat. Inst. Agric. Sci., Ser. D 3, 1-210 [In Japanese with English summary].

3. Fukui, K. (1974) Yakihata no Mura (Villages of Shifting Cultivation). Asahi Newspaper, Tokyo, Japan, pp. 419 [In Japanese].

4. Goodman, M. M. \& Bird, R.M. (1977) The races of maize IV: Tentative grouping of 219 Latin American races. Econ. Bot., 31, 204-221.

5. Gouesnard, B. et al. (1997) Classification of French maize populations based on morphological traits. Agronomie, 17, 491-498.

6. Harada, K., Huan, N.V. \& Yamamoto, M. (2006) Collection of maize local varieties in the Shikoku Mountains. Shikoku J. Crop. Sci. 43, 1-11 [in Japanese with English summary].

7. Hoshikawa, K. (1999) Shokuyou Sakumotsu (Edible Crops). Yokendo, Tokyo, pp. 697 [In Japanese].

8. Llaurado, M. \& Moreno-Gonzalez, J. (1993) Classification of northern Spanish populations of maize by method of numerical taxonomy. I. Morphological traits. Maydica, 38, $15-21$.

9. Mochizuki, N. (1968) Classification of maize lines and selection of breeding materials by the application of principal component analysis. Bull. Natl. Inst. Agric. Sci., Ser. D 19, 85-149 [In Japanese with English summary].

10. Rebourg, C., Gouesnard, B. \& Charcosset, A. (2001) Large scale molecular analysis of traditional European maize populations. Relationships with morphological variation. Heredity 86, 574-587.

11. Sasaki, K. (1972) Nihon no Yakihata (Shifting Cultivation in Japan). Kokin Shoin, Tokyo [In Japanese].

12. Soma, M. (1962) The regional structure of shifting cultivation area in Shikoku Mountains. Mem. Ehime Univ., 4(1), 1-79 [In Japanese with English summary].

13. Tokunaga, M. (1980) Commentary (I). In Seiryoki, Nihon Nosho Zenshu (Japan Agriculture Classics Series) No. 10, Nobunkyo, Tokyo, 206-279 [In Japanese]. 